DOI: $10.17976 /$ jpps/2018.01.13

“...И ВСЕ-ТАКИ ОНА ВЕРТИТСЯ!"

(Читая новую книгу Виктора Кувалдина)

\title{
B.О. Печатнов
}

ПЕЧАТНОВ Владимир Олегович, доктор исторических наук, профессор, зав. кафедрой стран Европы и Америки МГИМО МИД России. Для связи с автором: vopechatnov@gmail.com

Печатнов В.О. “...И все-таки она вертится!” (Читая новую книгу Виктора Кувалдина). - Полис. Политические исследования. 2018. № 1. С. 184-191. https://doi.org/10.17976/jpps/2018.01.13

Статья поступила в редакцию: 14.09.2017. Принята к публикации: 12.10.2017

\begin{abstract}
Аннотация. Статья посвящена некоторым ключевым проблемам и противоречиям глобализации, поднятым в вышедшей книге видным политологом и историком Виктором Кувалдиным “Глобальный мир. Политика. Экономика. Социальные отношения". Основное внимание исследователь уделяет проблеме “демократического дефицита" глобализации и перспективам переустройства современного миропорядка с целью эффективного повышения способности управлять современными глобальными процессами. Неолиберальная глобализация по сегодняшним западным стандартам сталкивается с серьезными вызовами со стороны как собственных обществ, так и новых центров силы за пределами Запада. Чтобы успешно избежать крупных потрясений в своих странах, западные элиты должны сделать глобализацию более приемлемой для собственных народов и более открытой, транспарентной и равноправной для поднимающихся центров мировой политики.
\end{abstract}

Ключевые слова: Виктор Кувалдин; глобализация; глобальное управление; капитализм; демократия; интеграция.

О глобализации во всем мире написаны тысячи книг - pro et contra, научных и публицистических, серьезных и просто как дань моде. Причем сама мода эта в последние годы радикально изменилась. Если раныше глобализация рисовалась в качестве безальтернативного магистрального пути развития, который неизбежно ведет все человечество к светлому будущему, то после событий последних лет этот бодрый детерминизм сменился как минимум скепсисом, а то и апокалипсическими предсказаниями краха глобализации, который одни предвидят с большой тревогой, а другие - с нескрываемым злорадством. Проблематика глобализации оказалась в центре политической борьбы и резко политизировалась, что отнюдь не способствует ее объективному изучению. На этом фоне недавняя работа В.Б. Кувалдина [Кувалдин 2017] - одного из ведущих российских исследователей глобальных процессов - выгодно выделяется своим академическим хладнокровием. Автор - давний адепт глобализации, но это не мешает ему видеть порождаемые ею проблемы и противоречия, равно как и огромные трудности на пути дальнейшего развития.

Книга Кувалдина необычна по своему замыслу и исполнению. Для всестороннего исследования становления глобального мира автор использует разные уровни анализа. Первая глава написана в теоретико-методологическом ключе, во второй приводится анализ общемировых процессов глобализации в их экономическом, социально-политическом и культурном измерении, далее автор переходит к рассмотрению основных акторов и макрорегиональных комплексов глобального мира, их роли и места в процессах глобализации. 
Должное место уделяется России и постсоветскому пространству. Все это создает целостную и предметную картину становления этого мира во всей его многослойности и динамике, что развивает предыдущие работы Кувалдина и ставит его новую книгу на особое место в глобалистике. Несмотря на все препятствия и срывы, процесс этого становления, доказывает автор, неумолимо идет вперед, движимый прежде всего экономической глобализацией “формированием глобальных рынков капитала, товаров, услуг, рабочей силы, трансмировых производственных комплексов, общепланетарных систем контроля и регулирования различных сторон хозяйственной деятельности” [там же: 28].

В каждом из разделов работы В.Б. Кувалдина немало интересных выводов и положений, как, например, тезис о превращении глобализации из западного проекта в "общечеловеческое предприятие" [там же: 45], хотя в последнее время многие политологи с растущим скептицизмом пишут о глобализации и все чаще употребляют такой сравнительно новый термин, как глоболокальность, в котором акцент перемещается на региональные и локальные процессы. Насыщенный огромным фактическим материалом, третий, самый объемный раздел книги по сути представляет собой энциклопедию регионоведческих знаний, своеобразную анатомию состояния основных региональных центров мира. Книга не менее интересна и самими постановками проблем, многие из которых располагают к дальнейшим размышлениям. Именно на них и имеет смысл остановиться подробнее.

Считается, что глобальный мир порождает и глобальную культуру, опирающуюся на некие универсальные ценности. Стандартное объяснение, которого придерживается и Кувалдин, - глобализация как новый, планетарный по своим масштабам, вариант капиталистического производства, ведет к распространению преимущественно западных ценностей - свободного рынка, “прав человека и демократических норм в качестве основ политической организации общества” [там же: 14-16]. Вместе с тем сам автор признает, что лидерство в глобализационных процессах постепенно переходит к Восточной Азии (“любимому дитяти глобализации”), которая имеет свою, альтернативную европейской, систему ценностей, включая иное понимание демократии, прав и свобод личности, и что “восточноазиатская система ценностей может быть приемлема и даже востребована в других частях света" [там же: 215]. А значит, ответ на вопрос о том, какие ценности несет с собой глобализация, далеко не так однозначен, как кажется на первый взгляд.

Но дело не только в этом. Подразумеваемый в подобной трактовке симбиоз капитализма и демократии сам по себе отнюдь не бесспорен. Напряженный и даже антиномичный характер отношений между капитализмом как способом производства и демократией как формой политической организации общества давно обсуждается политологами, историками и другими обществоведами [Шлезингер 1992; Закария 2004]. С одной стороны, капитализм (частная собственность, рыночная экономика, свободное предпринимательство) создает материальные предпосылки необходимого для демократии экономического и политического плюрализма. С другой - капитализм, ориентированный на максимизацию прибыли в интересах бизнеса и углубляющий социально-экономическое неравенство, противоречит демократическому идеалу политического равенства (один человек - один голос) и вполне может 
сочетаться с авторитарными и даже тоталитарными политическими режимами. Факт общеизвестный, но часто забываемый западными энтузиастами глобализации.

Особенно явственно это противоречие заявляет о себе на глобальном уровне. В рамках национального государства западные общества научились обуздывать рыночную стихию и произвол частного капитала с помощью демократических институтов, хотя это потребовало многих десятилетий политической борьбы и усилий гражданского общества. Укрощение глобального капитала - гораздо более сложная и пока нерешенная задача демократии. Транснациональные элиты, крупнейшие банки и ТНК, впервые в истории контролирующие столь большую часть мирового производства и капитала, по сути, действуют вне зоны демократического контроля, не встречая никакого организованного сопротивления, если не считать анархистского движения антиглобалистов. Эмбриональные институты глобального управления (ВТО, МВФ, ВБ, “семерка", “двадцатка") не только малоэффективны, но и сами недемократичны. В результате отсутствия на глобальном уровне демократической системы сдержек и противовесов процессы глобализации (особенно экономической) отражают прежде всего интересы глобального капитала, не считающегося с издержками для национальных государств и их населения. Лучше всего об этом говорит сам автор книги: "Неолиберальная глобализация бросает серьезный вызов демократическим институтам. Развязав руки рыночной стихии, она жестко ограничивает свободу действий легитимных органов власти на национальном уровне. Во времена 'тощих коров' мировые рынки диктуют свою волю законно избранным правительствам. Они вынуждены проводить сомнительную социально-экономическую политику, потому что этого от них ждут инвесторы, кредиторы, наднациональные институты. Мощное давление глобального капитала перевешивает ясно выраженную волю избирателей на очередных выборах. На очередных выборах для стоящих у руля наступает час расплаты по своим и чужим счетам, но и новое руководство оказывается зажатым в тех же тисках, навязывающих свою логику поведения" [Кувалдин 2017: 66].

Час расплаты наступает и для всей мировой экономики, которая, как показал кризис 2008-2009 гг., становится жертвой произвола и просчетов самого этого глобального капитала. Иными словами, ставки в его демократическом обуздании как никогда велики, а времени для решения этой проблемы очень немного [там же: 21].

Этот демократический дефицит, на наш взгляд, - главная на сегодня проблема глобализации, ее ахиллесова пята. Глобализация, как правильно отмечает автор, усугубляет многие внутренние проблемы западных стран - социальное неравенство, проблему иммиграции, стагнацию доходов большинства населения, не участвующего в глобальной экономике. Вместо прежнего размежевания между правыми и левыми в странах Запада возникает новый - социокультурный водораздел между “победителями” и “проигравшими” в глобальной экономике, который ветеран американской политической аналитики Т. Эдзалл описывает следующим образом: “Сторонники и противники 'традиционных ценностей', молодежь против пожилых, горожане против сельских жителей, люди с высшим образованием против не имеющих его, синие воротнички против белых воротничков, белые против цветных, иммигранты против коренных жителей”.

\footnotetext{
${ }^{1}$ Edsall T. 2017. The End of the Left and Right as We Knew Them. - The New York Times, 22.06. URL: https://www.nytimes.com/2017/06/22/opinion/nationalism-globalism-edsall.html (проверено 03.12.2017).
} 
Этот раскол порождает острое социальное недовольство, которое при отсутствии транснациональных демократических институтов находит выход на национальном уровне в виде протеста против политики и космополитических элит “своих" государств, потворствующих глобализации. Именно из протеста вырастают основные преграды на ее пути: евроскептицизм, получивший крайнее выражение в Брекзите, популизм и “экономический национализм”, которые привели к власти в США Д. Трампа и укрепили позиции правых партий Европы. Главное, по Виктору Кувалдину, противоречие современного глобального мира - " между планетарным масштабом многих видов человеческой деятельности, особенно хозяйственной, и национальногосударственными формами организации политического пространства" [там же: 20] - проявляется в конфликте между глобализацией и национализмом как традиционалистской реакцией на издержки глобализации. Хотя этот протест подчас принимает весьма уродливые и даже экстремистские формы, он представляет своеобразный демократический бунт значительной части национальных сообществ против неолиберальной глобализации и глобальных элит [Lieven 2017: 23]. Иными словами, демократия выступает скорее в оппозиции глобальному капитализму, чем в гармонии с ним.

Почему центром этой оппозиции стал Запад, еще недавно бывший главным мотором и бенефициаром глобализации? Автор подводит к ответу на этот вопрос, отмечая растущие издержки глобализации для западных стран и фиксируя изменение их отношения к ней [Кувалдин 2017: 44-46]. Однако в свете Брекзита и избрания Трампа - двух главных политических потрясений 2016 г., которые В.Б. Кувалдин не имел возможности учесть в книге, этот вопрос нуждается в более развернутом анализе, ибо помимо ударившего по Западу экономического “бумеранга глобализации”, о котором давно предупреждали российские ученые, в частности, патриарх российской политологии А.А. Галкин, здесь действуют и социально-культурные факторы: привычка населения Запада к высокому уровню жизни, которая делает стагнацию этого уровня и снижение былого социального статуса для него особенно болезненными, а также обострение проблемы иммиграции и сохранения национальной идентичности в условиях глобализации. Неслучайно наиболее подверженными вирусу популизма и экономического национализма оказались флагманы западной цивилизации - "островные” США и Великобритания с их неолиберальной моделью экономики и культом национального суверенитета, тогда как страны с более высокой степенью интегрированности и социальной защиты, более эгалитарной политической культурой и системной политикой смягчения издержек глобализации (ФРГ, Северная Европа) пострадали от него гораздо меньше [Hu, Spence 2017: 58-59].

Последствия этого англо-американского сбоя очень серьезны, хотя и труднопредсказуемы в долгосрочной перспективе. В ближайшем будущем речь идет как минимум о замедлении экономической глобализации и пробуксовке самых масштабных интеграционных проектов последних лет под американской эгидой - Транстихоокеанского партнерства (ТТП), из которого США уже вышли, и Трансатлантического торгового и инвестиционного партнерства (ТТИП), судьба которого остается под вопросом. В обоих случаях расклад противоборствующих сил примерно одинаков: крупный бизнес, политические элиты и финансовые круги против широкой общественности, сопротивление которой политики не могут не учитывать. 
Что это - временная аберрация или новая долгосрочная тенденция? Ответ во многом будет зависеть от того, сумеет ли западное руководство (особенно в США) амортизировать издержки глобализации для уязвимой части общества, в том числе - за счет сокращения упомянутого демократического дефицита с тем, чтобы плоды глобализации распределялись более равномерно, а большая часть общества ощущала возможность влиять на государственную политику в данном вопросе. Потребуется, с одной стороны, сложный комплекс мер социально-экономического свойства, а с другой - нахождение путей подключения общественности к принимаемым решениям. Например, некоторые американские либералы предлагают ослабить монополию элит на ведение торговых переговоров за счет участия в них представителей общественности [Bernstein, Wallach; Ikenberry 2016]. В целом вопрос состоит в том, как сделать глобальный миропорядок, оторвавшийся от национальной почвы, приемлемым для национальных сообществ и их культур. "Мировой порядок, - отмечает американский международник У.Р. Мид, - должен базироваться не только на консенсусе элит и балансе сил, но и на свободном выборе национальных сообществ, которые нуждаются в защите от внешнего мира, хотя и стремятся пользоваться преимуществами взаимодействия с ним" [Mead 2017: 7].

Вторая часть этой проблемы и новой повестки дня для западных элит, о которых пишет В.Б. Кувалдин, - реформа сложившегося мирового порядка, “адаптация политических систем и международных институтов к потребностям интенсивного транспланетарного взаимодействия” [Кувалдин 2017: 21]. Налицо глубокое противоречие между реальностью и объективной необходимостью: “Позитивное развитие глобализации требует нового, гораздо более высокого уровня управляемости общественными процессами. Пока этой системы нет, и любые попытки ее создания сталкиваются с огромными трудностями" [там же: 22]. Автор не останавливается подробно на этих попытках, между тем вопрос о том, куда движется развитие глобального миропорядка и что происходит с его управляемостью, имеет ключевое значение для перспектив глобализации. Да и само содержание книги позволяет сделать некоторые, хотя бы предварительные, выводы. Большинство искушенных аналитиков сходится в том, что дальнейшая эволюция современного глобального мирового порядка, скорее всего, будет развиваться (и уже развивается, как показано в книге) по следующим основным направлениям.

Во-первых, он будет становиться все менее иерархическим и более плюралистическим не только по количеству игроков, но и по их внутреннему устройству - "смешанным", по выражению эксперта корпорации $R A N D$ M. Мазара [Mazarr 2017: 30-31]. На смену "американоцентристскому миру" западных демократий идет постамериканский мир, в котором все больший вес приобретают "нелиберальные демократии" и вовсе не демократические государства. В каком-то смысле здесь также встает проблема демократического дефицита, поскольку речь идет о подъеме других центров силы (Азии, России, Латинской Америки), требующих большей роли в глобальном управлении и придания ему более равноправного характера. Сможет ли Запад во главе с США поступиться своим привычным доминированием и пойти навстречу этим требованиям, сделав тем самым миропорядок более инклюзивным и приемлемым для его остальных участников? Или США поддадутся искуше- 
нию рефлекса холодной войны - объединить западные демократии против очередных “нарушителей” либерального порядка, будь то Китай, Россия или Иран? Ответ на этот вопрос остается открытым, хотя в современном мире реалистичность второго пути вызывает большие сомнения, а его риски (прежде всего - угроза прямого столкновения великих держав) представляются непомерными [ibid: 29]. Во времена Б. Обамы США, как убедительно показывает В.Б. Кувалдин, попытались двинуться в первом направлении, наполнив американское лидерство новым содержанием: вместо неприкрытого эгоизма, односторонних действий и силового диктата “доктрины Буша" перенести упор на организацию многостороннего сотрудничества в совместном решении глобальных проблем и тем самым сделать лидерство США более полезным и привлекательным для других стран и менее обременительным для самой Америки. При этом в официальных документах Соединенным Штатам отводилась роль уже не “шерифа”, диктующего остальным свои правила и надзирающего за их соблюдением, а "катализатора коллективных действий на службе общих интересов" ${ }^{2}$. На деле эта переориентация удалась далеко не полностью, а главное - не получила достаточно широкой поддержки внутри самих США. Победивший на последних выборах осенью 2016 г. "трампизм" постулирует возврат к национальному эгоизму вплоть до самоустранения Вашингтона от привычной роли мирового лидера. Пока трудно сказать, насколько далеко зайдет этот процесс в реальности и насколько оправданными окажутся распространенные опасения, что может возникнуть вакуум глобального лидерства в постамериканском мире. Но здесь есть и свои плюсы, поскольку даже частичное самоустранение Вашингтона может стимулировать другие центры силы к заполнению этого вакуума.

Вторая намечающаяся тенденция касается институциональной структуры изменяющегося миропорядка. По мнению ряда авторитетных экспертов, наряду с существующими институтами глобального управления будут возникать (и уже возникают) организованные по сетевому принципу неформальные коалиции, объединяющие правительства, экспертные группы и неправительственные организации для решения отдельно взятых глобальных проблем, таких как изменение климата или пандемии [Ikenberry 2016]. Это будут в полном смысле слова “коалиции желающих", добровольно принимающих на себя "суверенные обязательства", по выражению Р. Хаaca [Haass 2017: 2-3]. Наглядный прообраз такого многостороннего формата, совместимого с национальным суверенитетом, -Парижское соглашение по климату, которое администрация Трампа отказывается подписать. Подобные гибкие структуры потенциально способны продвинуть решение глобальных проблем без ущемления национального суверенитета и тем самым - ослабить одно из ключевых противоречий глобализации.

Процессы глобализации будут развиваться независимо от воли и желаний людей. “Даже если экономическая глобализация замедлится, - отмечает Дж. Най-мл., - технология создает экологическую, политическую и социальную глобализацию, которые потребуют кооперационных ответов" [Nye 2017: 16]. Весь вопрос в том, будет ли найден этот ответ - сможет ли человечество справиться с разрывом между императивом повышения управляемости глобаль-

\footnotetext{
${ }^{2}$ National Security Strategy 2010. URL: https://www.nssarchive.us/national-security-strategy-2010 (accessed 03.12.2017).
} 
ными процессами и нарастающей в мире энтропией в виде глобальных угроз и проблем. При всем своем оптимизме В.Б. Кувалдин вовсе не исключает, что мир может “зависнуть” перед лицом вызовов будущего, не в силах мобилизовать свой творческий потенциал и найти адекватные решения сложнейших проблем глобального мироустройства" [с. 27]. В таком случае человечество может быть отброшенным назад, к “доглобальным формам общественного бытия" [с. 399]. Действительно, мы имеем дело с непредсказуемостью исторического процесса, который таит в себе огромные созидательные и разрушительные силы. Книга Виктора Кувалдина - это еще и призыв к осознанию той громадной коллективной ответственности, которая лежит на человечестве за выбор своего дальнейшего пути.

Закария Ф. 2004. Будущее свободы: нелиберальная демократия в США и за их пределами. Пер. с англ. под ред. В.Л. Иноземцева. М.: Ладомир. 383 с.

Кувалдин В. 2017. Глобальный мир. Политика. Экономика. Социальные отношения. М.: Весь Мир. 400 с.

Шлезингер А., мл. 1992. Циклы американской истории. М.: Прогресс. 688 с.

Bernstein J., Wallach L. 2016. The New Rules of the Road: A Progressive Approach to Globalization. Petersen Institute of International Economics, October 13. URL: https:// piie.com/events/new-rules-road-progressive-approach-globalization (accessed 03.12.2017).

Haass R. 2017. World order 2.0. The Case for Sovereign Obligation. - Foreign Affairs. January-February. P. 2-9.

Hu F., Spence M. 2017. Why Globalization Stalled and How to Restart It. - Foreign Affairs. Vol. 96. No. 4 (July/August). URL: www.foreignaffairs.com/articles/world/2017-06-13/whyglobalization-stalled (accessed 03.12.2017).

Ikenberry J. 2016. Divided Nations: Why Global Governance Is Failing, and What We Can Do About It. - Foreign Affairs. URL: https://www.foreignaffairs.com/reviews/capsulereview/divided-nations-why-global-governance-failing-and-what-we-can-do-about-it (accessed 03.12.2017).

Lieven A. 2017. The New Nationalism. - The National Interest. P. 21-29.

Mazarr M. 2017. The Once and Future Order. - Foreign Affairs. January-February. P. 25-32.

Mead W. 2017. The Jacksonian Revolt. American Populism and the Liberal Order. Foreign Affairs. March-April. P. 2-7.

Nye Jr., Joseph S. 2017. Will the Liberal Order Survive? The History of an Idea. - Foreign Affairs. Vol. 96. No. 1 (January/February). P. 10-16.

DOI: $10.17976 /$ jpps/2018.01.13

\section{"...AND YET IT KEEPS REVOLVING": READING VICTOR KUVALDIN'S “THE GLOBAL WORLD”}

\section{V.O. Pechatnov ${ }^{1}$}

${ }^{1}$ Moscow State Institute of International Relations (MGIMO-University), MFA of Russia. Moscow, Russia

PECHATNOV Vladimir Olegovich, Dr. Sci. (Hist.), Professor, Head of the Department of the countries of Europe and America, MGIMO-University. Email: vopechatnov@gmail.com

Pechatnov V.O. “...And yet It Keeps Revolving”: Reading Victor Kuvaldin's “The Global World”. - Polis. Political Studies. 2018. № 1. C. 184-191. (In Russ.) https://doi.org/10.17976/jpps/2018.01.13 
Abstract. The article explores some key problems and contradictions of globalization raised by a prominent political scientist and historian Victor Kuvaldin in his new book The Global World. Politics. Economics. Social Relations. The main attention is devoted to globalization's "democratic deficit" and prospects of reforming the present world order to efficiently improve global governance. The contemporary neo-liberal globalization project sponsored by the West is facing serious challenges both at home and vis-a-vis other non-Western power centers. In order for globalization to successfully proceed without major upheavals in their respective countries, the Western elites have to make it more transparent and sustainable for their own populations and more inclusive for the rising new powers.

Kew words: Victor Kuvaldin; globalization; global governance; capitalism; democracy; integration.

\section{References}

Bernstein J., Wallach L. The New Rules of the Road: A Progressive Approach to Globalization. Petersen Institute of International Economics. October 13, 2016. URL: https://piie.com/events/new-rules-roadprogressive-approach-globalization (accessed 03.12.2017). P. 2-9.

Haass R. World Order 2.0. The Case for Sovereign Obligation. - Foreign Affairs. 2017. January/February.

Hu F., Spence M. Why Globalization Stalled and How To Restart It. - Foreign Affairs. 2017. Vol. 96. No. 4. URL: www.foreignaffairs.com/articles/world/2017-06-13/why-globalization-stalled/ (accessed 03.12.2017).

Ikenberry J. Divided Nations: Why Global Governance Is Failing, and What We Can Do About It. Foreign Affairs. 2016. URL: https://www.foreignaffairs.com/reviews/capsule-review/divided-nations-whyglobal-governance-failing-and-what-we-can-do-about-it (accessed 03.12.2017).

Kuvaldin V. Global'nyi mir. Politika. Ekonomika. Sotsial'nye otnosheniya [The Global World. Policy. Economy. Social Relations]. Moscow: Ves' Mir Publ. 2017. 400 p.

Lieven A. The New Nationalism. - The National Interest. 2017. July-August. P. 21-29.

Mazarr M. The Once and Future Order. - Foreign Affairs. 2017. January-February. P. 25-32.

Mead W. The Jacksonian Revolt. American Populism and the Liberal Order. - Foreign Affairs. 2017. March-April. P. 2-7.

Nye Jr., Joseph S. Will the Liberal Order Survive? The History of an Idea. - Foreign Affairs. 2017. Vol. 96. No. 1. January/February. P. 10-16.

Schlesinger A., Jr. The Cycles of American History. (Russ. ed.: Schlesinger A., Jr. Tsikly amerikanskoi istorii. Moscow: Progress Publ. 1992. 688 p.)

Zakaria F. The Future of Freedom: Illiberal Democracy at Home and Abroad. (Russ. ed.: Zakaria F. Budysheye svobody: neoliberal'naya demokratia v SShA iza ikh predelami. Moscow: Ladomir Publ. 2004. 383 p.) 